\title{
Factorial validity of the death obsession scale in African University students
}

\author{
Solomon Mashegoane ${ }^{a}$ and Malose S. Makhubela ${ }^{b}$ \\ aDepartment of Psychology, Un iversity of Limpopo, Polokwane, South Africa; 'bepartment of Psychology, Un iversity of Pretoria, Pretoria, \\ South Africa
}

\begin{abstract}
In this study the factor structure of the Death Obsession Scale (DOS) was examined using confirmatory factor analysis. Data used consisted of DOS reports of 328 Black African students. Confirmatory factor analysis revealed that two- and threefactor models obtained among female and male African students, respectively, provided the best fit to the data. The two factors in female African students were Death Rumination and Apprehension, and the three factors of their male counterparts were Death Ruminations, Apprehension, and Comprehensibility of Death. Factor intercorrelations did not resolve the dimensionality issue of the measure, leading to the conclusion that the factors must be investigated further.
\end{abstract}

Throughout history, death has conjured a sense of mystery and dread for many. Human existence is, according to Becker (1973, 1975), premised entirely on the denial of death and a construction of rituals and similar repetitive behaviors to ward off its impact. Averting mortality fears and seeking everlasting life have arguably remained the prime drivers of the world's foremost religions. Contemporary psychological research on death attitudes provides new perspectives on this phenomenon and its link to the human condition (Abdel-Khalek, 2002; Becker, 1973; Iverach, Menzies, \& Menzies, 2014; Neimeyer, Wittkowski, \& Moser, 2004).

Feifel's ground-breaking work relating death anxiety to health paved the way for the refinement of research on the psychology of death and dying (Feifel, 1990; Neimeyer et al., 2004). The development of a number of measurement instruments to assess death anxiety and its variants followed (Neimeyer, 2004; Neimeyer et al., 2004). Death anxiety measures were complemented with scales measuring obsessions and depression associated with death.

The rationale for constructing separate scales for death obsessions and depression in addition to death anxiety is as follows. Although features of death-related obsessions, depression and anxiety are incorporated in the death distress conceptual framework, and their respective measurement scales tend to overlap, they can be isolated as different constructs. Studies contrasting scales such as the Death Obsession Scale (DOS; Abdel-Khalek, 1998), the Death Depression Scale-revised (DDS-R; Templer et al., 2001-2002) and the Death Anxiety Scale (DAS; Templer, 1970), or their equivalents, have demonstrated that each of the constructs has sufficient variance to retain a distinctive identity (Alvarado, Templer, Bresler, \& ThomasDobson, 1992-1993; Siscoe, Reimer, Thomas-Dobson, \& Templer, 1992; Tomás-Sábado \& Limonero, 2007; Tomás-Sábado, \& Gómez-Benito, 2004, 2005). Thus, the DOS operationalizes death obsessions as recurrent cogitations and ideas about death; the DDS-R reflects symptomatic reactions to death ideas, and the sadness and unhappiness induced by the loss of a significant other or death in general; and the DAS is a unidimensional measure of the fear stemming from the sights, sounds, feelings, and thoughts about death and dying.

The DOS was developed by Abdel-Khalek (1998) as a measure of the third element of the triadic death distress construct that encompasses death anxiety and death depression (Abdel-Khalek, 2004; Maltby \& Day, 2000). The factorial structure of the DOS has since been determined in a number of studies using different samples in diverse milieus. All the studies used exploratory factor analysis (EFA), and did so using either principal component (PCA) or principal axis (PA) factoring. Most followed that by oblique rotation of the factors, based on the assumption that the DOS measures a single characteristic and therefore its factors are correlated. In

CONTACT Solomon Mashegoane solomon.mashegoane@ul.ac.za Office 1021, M Block, University of Limpopo, University Road, Mankweng, Polokwane, 0727, South Africa.

The article is a reanalysis of the data first presented by S Mashegoane and S Moripe as "Structure of the Death Obsession Scale among South African University Students" at the 7th Annual International Conference on Psychology, May 27-30, 2013 in Athens, Greece. 
Table 1. Item loadings of the factor structures of the death obsession scale (DOS) from varied exploratory factor an alytic studies.

\begin{tabular}{|c|c|c|c|c|}
\hline Model & Sample & & Factors and item loadings & \\
\hline & & Factor 1 & Factor 2 & Factor 3 \\
\hline 1 & $\begin{array}{l}\text { Kuwaiti students; Female } \\
\text { Palestinian refugees }\end{array}$ & General Death Obsession (All items) & & \\
\hline $2 a$ & US students & $\begin{array}{l}\text { Death Rumination }(4,5,7,8,9,10,11 \text {, } \\
\quad 12,15)\end{array}$ & $\begin{array}{l}\text { Death Dominance and Repetition } \\
(1,2,3,6,13,14)\end{array}$ & \\
\hline $2 b$ & Iranian students & $\begin{array}{l}\text { Death Rumination and Dominance } \\
\quad(2,3,4,5,6,7,8,12,15)\end{array}$ & $\begin{array}{l}\text { Death Idea Worry }(1,9,10,11,13 \text {, } \\
\text { 14) }\end{array}$ & \\
\hline $2 c$ & Female African students, & Death Rumination $(3,4,5,6,7,8,9)$ & Apprehension $(11,13,14,15)$ & \\
\hline $3 a$ & $\begin{array}{r}\text { Egyptian students, British } \\
\text { students, British adults }\end{array}$ & $\begin{array}{l}\text { Death Rumination }(3,4,5,7,8 \text {, } \\
\quad 9,10,12)\end{array}$ & Death Dominance $(1,2,6,15)$ & $\begin{array}{l}\text { Death Idea Repetition }(11,13 \text {, } \\
\text { 14) }\end{array}$ \\
\hline $3 b$ & Palestinian men & Death Rumination $(3,4,5,8,9,10,12)$ & Death Dominance $(1,2,7,15)$ & $\begin{array}{l}\text { Death Idea Repetition }(6,11 \text {, } \\
13,14)\end{array}$ \\
\hline $3 c$ & Spanish students & $\begin{array}{l}1,3,5,7,8,9,10,11,12 \text { (Death } \\
\text { Rumination) }\end{array}$ & $\begin{array}{l}\text { Sudden Death Dominance }(4,6, \\
13,14)\end{array}$ & Death Brooding $(2,15)$ \\
\hline $3 d$ & Male African students & Death Rumination $(3,4,5,6,7,10,12)$ & Apprehension $(11,13,14,15)$ & $\begin{array}{l}\text { Comprehensibility of Death } \\
(1,2)\end{array}$ \\
\hline
\end{tabular}

Note: Model $1=$ Abdel-Khalek and Lester (2003), Abdel-Khalek et al. (2006); Model 2a =Abdel-Khalek and Lester (2003); Model 2b=Rajabi (2009); Model $2 c=$ Mashegoane and Moripe (2013); Model 3a=Abdel-Khalek (1998), Maltby and Day (2000); Model 3b=Abdel-Khalek et al. (2006); Model $3 c=$ Tomás-Sábado and Gómez-Benito (2002-2003); Model 3d = Mashegoane and Moripe (2013).

contrast, Abdel-Khalek and Lester (2003) used varimax rotation, an orthogonal technique. So far, only Rajabi (2009) conducted confirmatory factor analysis (CFA) in addition to EFA, as discussed below.

EFA of the DOS has yielded one-, two-, and threefactor solutions (see Table 1). Abdel-Khalek and Lester (2003) obtained a single factor model among Kuwaiti students, and Abdel-Khalek, Al-Arja, and Abdalla (2006) found the same factor structure studying Palestinian women refugees. They both called the factor General Death Obsession. This was one of two instances when a factor structure of two studies contained identical item loadings. A two-factor model was obtained by Abdel-Khalek and Lester (2003) among American students, as did Rajabi (2009) among Iranian students, and Mashegoane and Moripe (2013) studying a sample of South African students. The first factor for AbdelKhalek and Lester (2003) and Mashegoane and Moripe (2013) was named Death Rumination; in Rajabi (2009) it was called Death Rumination and Dominance. The second factor was variably termed Death Dominance and Repetition, Apprehension, and Death Idea Worry in the three respective studies.

Finally, a three-factor model was obtained by AbdelKhalek (1998) among Egyptian students, Abdel-Khalek et al. (2006) among Palestinian refugees, Tomás-Sábado and Gómez-Benito (2002-2003) using Spanish students, and Mashegoane and Moripe (2013) among African students. Only two studies (Abdel-Khalek, 1998; Maltby \& Day, 2000) obtained common factors (Death Rumination, Death Dominance \& Death Idea Repetition), with completely matching item loadings. Although most studies refer to the first factor as Death Rumination(s), their factor items are not wholly the same. Similarly, Abdel-Khalek (1998), Abdel-Khalek et al. (2006), and Maltby and Day (2000) referred to their second and third factors as Death Dominance and Death Idea Repetition, but the item content of the factors in the studies are not identical. Clearly, the factor structure of the DOS is far from being finalized.

This study seeks to apply CFA to investigate further the psychometric properties of the DOS, chiefly its factor structure. Both EFA and CFA are useful statistical methods to investigate psychometric properties such as item quality, internal reliability, and structure. Both techniques can be used for exploratory and confirmatory purposes. Nevertheless, CFA is suitable when there are now competing structures of the scale, as it is the case with the DOS. This means that in this study existing factor structures of the DOS will be specified a priori and compared using CFA.

The study will go beyond the CFA approach used by Rajabi (2009), by extending analysis to all available factor structures of the DOS, and also determining the importance of gender in the analysis. We first evaluate the factor structure formulated by Abdel-Khalek (1998) using CFA with our student sample. Following this, we evaluate whether any of the five alternative factor models or the two- and three-factor models by Mashegoane and Moripe (2013) are superior to the first model. With the alternative models we check their fit and compare them to the reference model (AbdelKhalek, 1998). The study is particularly important since the unveiling of different types of obsessions is prioritized by practitioners and researchers, and valid customized scales are needed (Taylor et al., 2014).

\section{Method}

\section{Participants}

The present study represents a secondary analysis of data previously collected on the death obsession scale 
in a South African setting (Mashegoane \& Moripe, 2013). The sample, consisting of 328 Black African students, was drawn from a predominantly Black university in Limpopo, South Africa using a convenience sampling method. The students' average age was 21.02 years $(S D=2.91)$ with a range from 17 to 42 years. An overwhelming $(99.4 \%)$ number of them reported that they were single. About $64.3 \%$ of the students were female and nearly $68 \%$ had a rural home background.

\section{Instrument}

The DOS was developed by Abdel-Khalek (1998) to measure death-related obsessions. It is a 15-item scale using a five-step response format. Respondents are asked to rate each of the 15 death obsession items from 1 (no) to 5 (very much). Thus, the scale has a possible score range of 15 to 75 . A high score implies preoccupation with death ideas and thoughts, a high obsession with death. Items of the scale, first developed in Arabic and subsequently applied in English, are spread across the three dimensions of Death Rumination (e.g., "I find it greatly difficult to get rid of thoughts about death"), Death Dominance (e.g., "A feeling that I will die suddenly overtakes me"), and Death Idea Repetition (e.g., "The recurrence of the idea of death annoys me") in the origination study (Abdel-Khalek, 1998; Maltby \& Day, 2000). In subsequent studies, the factor structure of the DOS oscillates between one-, two-, and threefactor solutions (see Table 1). Even so, it demonstrates high internal consistency for the total scale and the subscales, good one-week test-retest reliability, and face, construct, and discriminant validity (AbdelKhalek, 1998; Abdel-Khalek \& Lester, 2003; Maltby \& Day, 2000).

Mashegoane and Moripe (2013) compared male and female students' DOS average scores to determine if there were any significant differences. It turned out that there were score differences $(p=0.001-0.050 ; d=0.22$ 0.35 ), with female students scoring comparatively higher mean values on nine of the DOS items. Although the effect sizes were not large, they nevertheless were important, and the respective $t$-scores were all equal to or greater than 1.96. Analysis then proceeded along the lines of gender on the strength of the $t$-test findings.

Mashegoane and Moripe (2013) subjected female students' DOS data to PCA. The initial check for factorability suggested that there were no violations of analytic assumptions, and the adequacy of sampling for the whole scale was high $(\mathrm{KMO}=0.92, p<0.05)$. Four items, namely, Items 2 ("The idea that I will die at a young age dominates me"), 1 ("Some questions about death come to my mind which I am unable to answer"),
12 ("I think about death continually"), and 10 ("I find myself rushing to think about death") were gradually removed after inspection of communalities because the factor solution explained less than half $(<50 \%)$ of the original variances. A two-factor solution was obtained for female students, explaining $49 \%$ and $11 \%$ of variance for Factors 1 and 2, respectively. The factors were named Death Rumination and Apprehension. The naming of Factor 1 was influenced by Abdel-Khalek (1998) and Maltby and Day (2000).

Male students' data for the DOS was also assessed for factorability. For this group too, there were no analytic assumption violations. However, the ratio of cases to variables in the case of males did not reach the ideal level, yet it was deemed acceptable. The scale's adequacy of sampling was meritorious at $\mathrm{KMO}=0.88, p<0.05$. Two items, namely, Items 9 ("I have exaggerated concern with the idea of death") and 8 ("The idea of death overcomes me"), were removed on the first and second iterations, because the factor solution explained less than half $(<50 \%)$ of the original variances. Threefactors were extracted for male students, and they explained $41 \%, 10 \%$, and $9 \%$ of variance for Factors 1,2 , and 3, correspondingly. The factors were called Death Rumination, Apprehension, and Comprehensibility of Death. Once more, the name Death Rumination was retained for Factor 1. Factor 2 was so named because of its similarity to the female factor with the same name.

\section{Procedure}

Data collection involved the administration of the DOS as part of a battery of measures to groups of students outside of their normal university hours (Mashegoane \& Moripe, 2013). The purpose of the study was explained and students were also informed about their rights as participants. For instance, they were made aware about the voluntary nature of their participation, and the right to withdraw at any stage of the study without giving reasons to do so. The students were not paid for taking part in the study, and at the end of each data collection session they were debriefed.

\section{Results}

\section{Data analysis}

The SEM testing was based on maximum likelihood estimation using AMOS 22.0 (Arbuckle, 2013) to assess how well the specified models adequately described the data. All factors were allowed to correlate. To identify the most significant and meaningful model 
modifications, we examined the modification indices and added paths that were most likely to improve the fit of the model and that made theoretical sense. To evaluate model fit, the independence model was compared to the hypothesized and respecified models. With the absence of consensus in the literature on preferred fit indices (e.g., Bentler, 1990; Hu \& Bentler, 1995, 1999; Kline, 2005), it was sensible that several goodness-of-fit indices (absolute, incremental, and parsimonious fit), modification indices, associated expected parameter changes, and residual error terms (Arbuckle \& Wothke, 1999) be used to evaluate model fit in the current study.

The indices used to assess the goodness-of-fit of the models included the chi-square statistic to $d f$ ratio $\left(\chi^{2} / d f\right)$, the comparative fit index (CFI), the normed fit index (NFI), the Tucker-Lewis index (TLI), Akaike's information criterion (AIC), expected cross-validation index (ECVI), and the root mean square error of approximation (RMSEA) along with its related $90 \%$ confidence interval. Models were accepted as providing good fit if $\chi^{2} / d f<1.5$, TLI and CFI $\geq 0.95$, RMSEA $<0.06$, and NFI $>0.90$ (see Bentler, 1990; Bentler \& Bonett, 1980; Hu \& Bentler, 1995; Kline, 2005). To compare the fit for the competing models, we used AIC and the ECVI; the lower the values on both indices, the superior the fit of the model to the data. Descriptive statistics for the total scale and each item were derived and assessed for normality. The frequency distribution of the DOS total scale scores and each item scores approximated a nonnormal distribution. Skewness values ranged from 0.361 to 1.423 and kurtosis values ranged from -1.134 to 1.064 . This result of nonnormality was also confirmed by the Shapiro-Wilk test $=0.954, p<0.001$. As a result of this univariate nonnormality, bootstrapping was used to assess model fit (Efron \& Tibshirani, 1993).

\section{CFA}

CFA was applied to the DOS factor structures available in the literature to test for their factorial validity and compare them first against the reference model and then against each other. In all there were eight factor structure models, consisting of a single factor model, three varieties of two-factor models, and four three-factor models (Table 1). We first studied the fit of the model formulated by Abdel-Khalek (1998) for his sample of Alexandria University students. In our student sample, the values of the fit statistics for the NFI are acceptable; but the values for the CFI, TLI, and RMSEA indicate a poor fit of the model to the data (Table 2). We then determined the fit of the alternative two- and three-factor models (Table 1). Results for the two- and three-factor models by Mashegoane and Moripe (2013) revealed a better fit to the data. The $\chi^{2} / d f$ ratio and the RMSEA and its $90 \%$ interval were below the threshold of acceptability, the NFI, TLI, and CFI were above the base recommended level of good fit, and the AIC and ECVI were, respectively, the lowest among the models ( $p s>0.001$; see Table 2).

As for the remaining five alternative models, we generally observed that none of them has acceptable fit to the data. This is evidenced by TLI and CFI values $<0.95$, RMSEA values $>0.06$, and NFI values $<0.9$. With the comparison of all the models based on the AIC and the ECVI (Table 2), we further concluded that compared to the reference model of Abdel-Khalek (1998) and the alternative models, a superior fit in the student sample is present in both of the models by Mashegoane and Moripe (2013), especially their twofactor model.

All parameter estimates were viable and statistically significant in both of the Mashegoane and Moripe (2013) models. All items loaded statistically and practically significantly on their respective factor (regression coefficients ranged from 0.565 to $1.352, p<0.001$; see Figures 1 and 2). The correlation between the factors in the two-factor model is $0.878, p<0.001$ which is both statistically and practically significant. The two-factor model also contains correlations between residual variances. Likewise, the intercorrelations between the factors in the three-factor model were all statistically and

Table 2. Model fit estimates of the confirmatory factor analyses.

\begin{tabular}{|c|c|c|c|c|c|c|c|c|c|}
\hline Model & & $\mathrm{df}$ & $\mathrm{NFI}$ & TLI & $\mathrm{CFI}$ & RMSEA & AIC & RMSEA $(90 \% \mathrm{Cl})$ & ECVI \\
\hline Model 1 & 242.145 & 90 & 0.885 & 0.898 & 0.923 & 0.072 & 332.145 & $0.061-0.083$ & 1.010 \\
\hline Model 2a & 242.145 & 89 & 0.885 & 0.896 & 0.923 & 0.072 & 334.145 & $0.061-0.083$ & 1.016 \\
\hline Mode $2 \mathrm{~b}$ & 225.140 & 89 & 0.893 & 0.907 & 0.931 & 0.068 & 317.140 & $0.057-0.079$ & 0.964 \\
\hline Model 2c & 25.169 & 34 & 0.978 & 1.013 & 1.000 & 0.000 & 89.169 & $0.000-0.027$ & 0.425 \\
\hline Model 3a & 206.307 & 87 & 0.902 & 0.917 & 0.940 & 0.065 & 302.307 & $0.053-0.076$ & 0.919 \\
\hline Model 3b & 266.839 & 88 & 0.873 & 0.877 & 0.910 & 0.079 & 360.839 & $0.068-0.089$ & 1.097 \\
\hline Model $3 c$ & 236.587 & 87 & 0.887 & 0.896 & 0.925 & 0.072 & 332.587 & $0.061-0.083$ & 1.011 \\
\hline Model 3d & 79.085 & 62 & 0.863 & 1.015 & 0.966 & 0.049 & 163.085 & $0.000-0.079$ & 1.443 \\
\hline
\end{tabular}

Note: Model 1 = Abdel-Khalek and Lester (2003), Abdel-Khalek et al. (2006); Model 2a =Abdel-Khalek and Lester (2003); Model 2b=Rajabi (2009); Model 2c=Mashegoane and Moripe (2013); Model 3a=Abdel-Khalek (1998), Maltby and Day (2000); Model 3b=Abdel-Khalek et al. (2006); Model $3 c=$ Tomás-Sábado and Gómez-Benito (2002-2003); Model 3d = Mashegoane and Moripe (2013). 


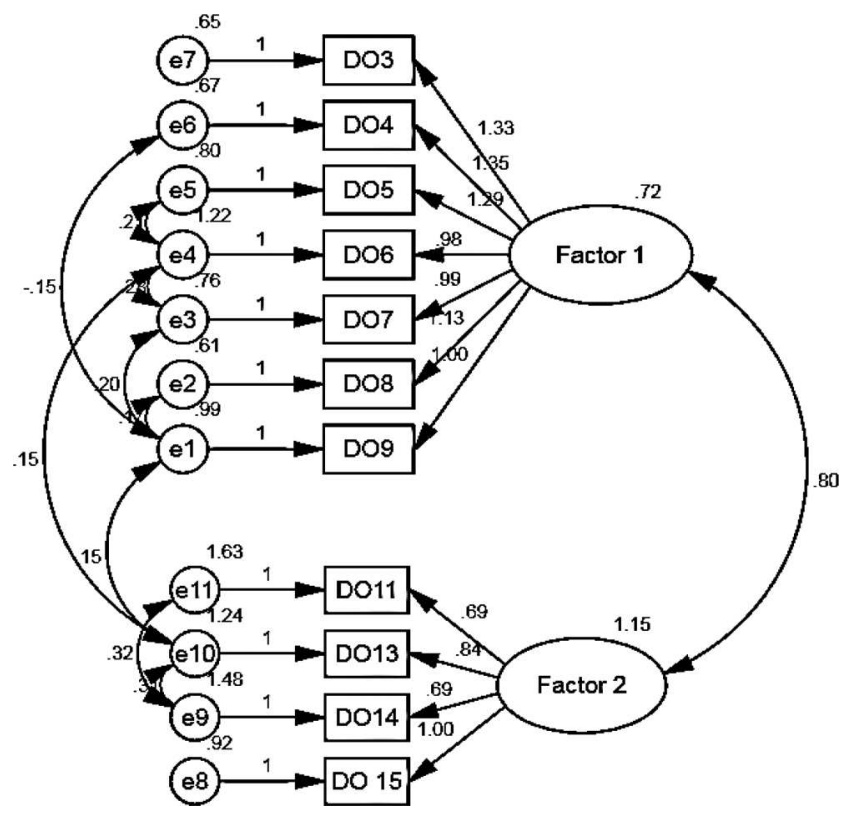

Figure 1. Pattern coefficients for the two-factor model: Female studen ts. The values on the path diagram are standardized regression coefficien ts, with arrows poin tin gfrom laten t variables to the observed variables.

practically significant $(r=0.768,0.656$, and 0.493 , $p<0.001$, respectively).

\section{Reliability}

Internal consistency for the total DOS scale and the subscales were calculated using Cronbach's coefficient

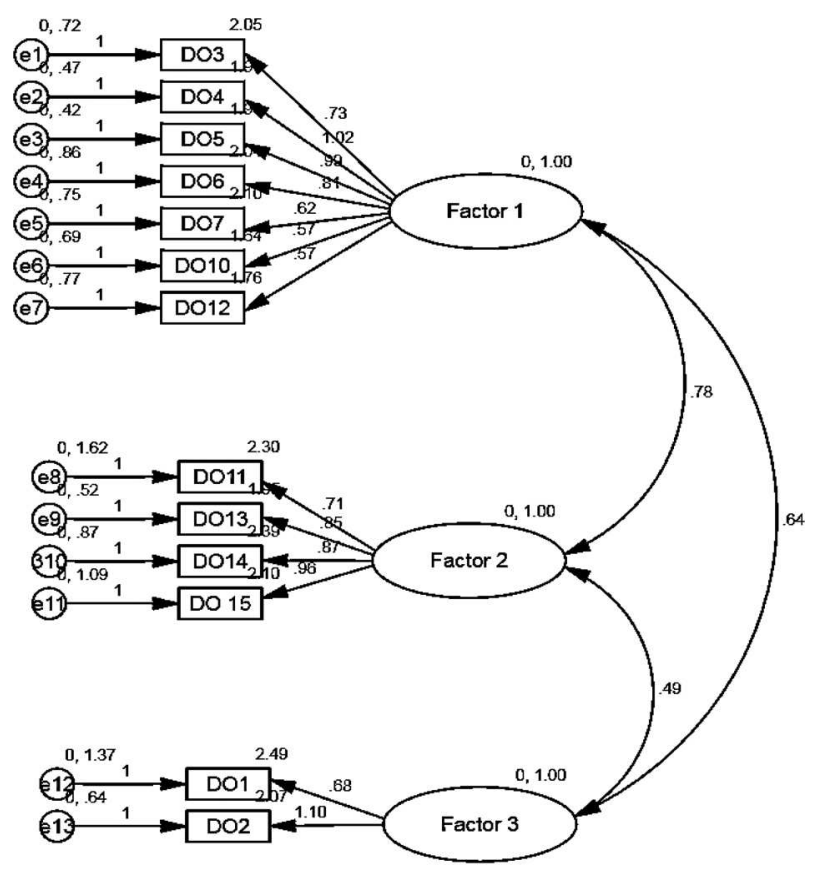

Figure 2. Pattern coefficients for the three-factor model: Male students. The values on the path diagram are standardized regression coefficients, with arrows pointing from latent variables to the observed variables. alpha. These were moderate to high at $\alpha=0.907$ for the total scale, 0.889 for the Death Rumination subscale (two-factor model), 0.741 for the Apprehension subscale (two-factor model), 0.867 for the Death Rumination subscale (three-factor model), 0.741 for the Apprehension subscale (three-factor model), and somewhat weaker at 0.519 for the Comprehensibility of Death subscale (three-factor model). Although the reliability estimates are generally good, they are inconsistent with the comparatively higher estimates found in past studies with university samples (Abdel-Khalek, 1998; Abdel-Khalek \& Lester, 2003; Maltby \& Day, 2000).

\section{Discussion}

In this study we evaluated the fit of the DOS factor structures found in the literature, with South African students. Only the two- and three-factor models obtained by Mashegoane and Moripe (2013) had a better fit. However, our findings could not settle the issue of the dimensionality of the measure. The two factors found among Mashegoane and Moripe's female students had a very high correlation, suggesting that the DOS may after all be unidimensional. This is also supported by the correlations between residual variance components of items that load on the two underlying dimensions. But the three factors found among male students suggested a delineation of the dimensions of the DOS. Moreover, the moderate correlations between the factors indicated adequate discriminant validity between the related aspects of death obsession. As posited by the theory, the scales measure related but still separate aspects of death obsession (Abdel-Khalek, 1998). We conclude on the basis of the total results of the study that the factor structure, and thus the dimensionality, of the DOS is far from settled. We recommend that, in view of this unresolved issue of the dimensionality of the scale, researchers report not only the factor/ subscale scores but also the total DOS scale score. This study needs to be replicated, and extended to other populations, such as nonstudent, clinical populations. Future research should also ensure that there is numerical balance between female and male respondents if the purpose is to draw inferences across both genders.

\section{References}

Abdel-Khalek, A. M. (1998). The structure and measurement of death obsession. Personality and Individual Differences, 24, 159-165. doi:10.1016/s0191-8869(97)00144-x

Abdel-Khalek, A. M. (2002). Death obsession in Egyptian samples: Differences among people with anxiety disorders, 
schizophrenia, addictions, and normals. Death Studies, 26, 413-424. doi:10.1080/07481180290087384

Abdel-Khalek, A. M. (2004). A general factor of death distress in seven clinical and non-clinical groups. Death Studies, 28, 889-898. doi:10.1080/07481180490491040

Abdel-Khalek, A. M., Al-Arja, N. S., \& Abdalla, T. (2006). Death obsession in Palestinians. Death Studies, 30, 203-215. doi:10.1080/07481180500493302

Abdel-Khalek, A. M., \& Lester, D. (2003). Death obsession in Kuwaiti and American college students. Death Studies, 27, 541-553. doi:10.1080/07481180302881

Alvarado, K. A., Templer, D. I., Bresler, C., \& ThomasDobson, S. (1992-1993). Are death anxiety and death depression distinct entities? Omega-The Journal of Death and Dying, 26, 113-118. doi:10.2190/20hl-33jr-vabj-dltw

Arbuckle, J., \& Wothke, W. (1999). Amos 4.0 user's guide. Chicago: SPSS, Inc.

Arbuckle, J. L. (2013). IBM SPSS Amos 22 user's guide. Crawfordville, FL: Amos Development Corporation.

Becker, E. (1973). The fear of death. New York, NY: Free Press.

Becker, E. (1975). Escape from evil. New York, NY: Free Press.

Bentler, P. M. (1990). Comparative fit indexes in structural models. Psychological Bulletin, 107, 238-246.

Bentler, P. M., \& Bonett, D. G. (1980). Significance tests and goodness of fit in the analysis of covariance structures. Psychological Bulletin, 88, 588-606. doi:10.1037//00332909.88.3.588

Efron, B., \& Tibshirani, R. J. (1993). An introduction to the bootstrap. New York, NY: Chapman \& Hall.

Feifel, H. (1990). Psychology and death: Meaningful rediscovery. American Psychologist, 45, 537-543.

Hu, L.-T., \& Bentler, P. M. (1995). Evaluating model fit. In R. H. Hoyle (Ed.), Structural equation modeling: Concepts, issues, and applications (pp. 76-99). Thousand Oaks, CA: Sage.

Hu, L., \& Bentler, P. M. (1999). Cutoff criteria for fit indexes in covariance structure analysis: Conventional criteria versus new alternatives. Structural Equation Modeling, 6, 1-55. doi:10.1080/10705519909540118

Iverach, L., Menzies, R. G., \& Menzies, R. E. (2014). Death anxiety and its role in psychopathology: Reviewing the status of a transdiagnostic construct. Clinical Psychology Review, 34, 580-593.

Kline, R. B. (2005). Principles and practice of structural equation modeling (2nd ed.). New York, NY: Guilford.

Maltby, J., \& Day, L. (2000). The reliability and validity of the=death obsession scale among English university and adult samples. Personality and Individual Differences, 28, 695-700. doi:10.1016/s0191-8869(99)00131-2

Mashegoane, S., \& Moripe, S. (2013, May 27-30). Structure of the Death Obsession Scale among South African university students. Paper presented at the 7th Annual International Conference on Psychology, Athens, Greece.

Neimeyer, R. A. (2004). Constructions of death and loss: Evolution of a research program. Personal Construct Theory and Practice, 1, 8-20. Retrieved from http://www.pcpnet. org/journal/pctp04/neimeyer04.pdf

Neimeyer, R. A., Wittkowski, J., \& Moser, R. P. (2004). Psychological research on death attitudes: An overview and evaluation. Death Studies, 28, 309-340. doi:10.1080/ 07481180490432324

Rajabi, G. (2009). The psychometric properties of death obsession scale in freshman undergraduate students. Journal of Applied Sciences, 9, 360-365. doi:10.3923/ jas.2009.360.365

Siscoe, K., Reimer, W., Thomas-Dobson, A., \& Templer, D. I. (1992). Death depression versus death anxiety: Exploration of different correlates. Psychological Reports, 71, 1191-1194. doi:10.2466/pr0.1992.71.3f.1191

Taylor, S., McKay, D., Miguel, E. C., De Mathis, M. A., Andrade, C., Ahuja, N.,... Storch, E. A. (2014). Musical obsessions: A comprehensive review of neglected clinical phenomena. Journal of Anxiety Disorders, 28, 580-589. doi:10.1016/j.janxdis.2014.06.003

Templer, D. I. (1970). The construction and validation of a death anxiety scale. The Journal of General Psychology, 82, 165-177. doi:10.1080/00221309.1970.9920634

Templer, D. I., Harville, M., Hutton, S., Underwood, R., Tomeo, M., Russell, M.,..., \& Arikawa, H. (2001-2002). Death Depression Scale-revised. Omega-The Journal of Death and Dying, 44, 105-112.

Tomás-Sábado, J., \& Gómez-Benito, J. (2002-2003). Psychometric properties of the Spanish adaptation of the Death Obsession Scale (DOS). Omega - The Journal of Death and Dying, 46, 263-272. doi:10.2190/4b2c-mk8j-x8yj-9x4 m

Tomás-Sábado, J., \& Gómez-Benito, J. (2004). Death anxiety and death obsession in Spanish students. Perceptual and Motor Skills, 98, 31-34. doi:10.2466/pms.98.1.31-34

Tomás-Sábado, J., \& Gómez-Benito, J. (2005). Death anxiety and death depression in Spanish nurses. Psychological Reports, 97, 21-24. doi:10.2466/pr0.97.5.21-24

Tomás-Sábado, J., \& Limonero, J. T. (2007). Death depression and death obsession: Are they different constructs? Psychological Reports, 100, 755-758. doi:10.2466/pr0.100.3. 755-758 